\title{
Reassembling the Social Environment: A Network Approach to Human Behavior
}

\author{
Dhrubodhi Mukherjee
}

\begin{abstract}
This paper critically examines the influence of the structural elements of human behavior that are often neglected in social work literature (Robbins et al., 1998). It incorporates a new multi-theoretical framework that critically examines the significance of a network approach in analyzing social, ideological, and economic structures and their influence on individual actors. This paper discusses two interrelated theories: social network theory and social capital theory, and critiques their relevance in explaining human behavior for social work educators and professionals in an increasingly information-driven and electronically-interconnected global society. The author hopes that an expanded theory base will provide a holistic view of individual problems stemming out of inequitable social structure.
\end{abstract}

Keywords: Social capital, social network, structural analysis, network perspective, macro-theory

\section{INTRODUCTION}

Theoretical reflections are imperative to maintaining the integrity of the concepts involved when applied to empirical research. In this paper, two interrelated theories, namely, social network theory and social capital theory, will be critiqued to evaluate their relevance in understanding the influence of social structures on human behavior. The idea of conceptualizing social structure as networks of interconnected actors is comparatively new to social work. This approach, known as the network perspective, has been imported from electrical engineering to sociology in an attempt to understand the influence of social relations and interconnected ties on individual actors (Wasserman \& Faust, 1994). This paper argues that the network perspective is descriptively superior to the "person in environment" centric perspective simply because "it explicitly takes into account the social context within which actors make evaluations" (Burt, 1992, p. 8). This paper outlines the importance of incorporating the network approach into the matrix of human behavior theories.

Dhrubodhi Mukherjee, MSW, Ph.D. is assistant professor of Social Work, School of Social Work, Southern Illinois University Carbondale, Carbondale, IL 62901. 
In the 1970s, adoption of the "ecological perspective" experienced a shift from the classical social work definition of human behavior, which primarily focused on the behavior of the individual, to a broader, interdisciplinary approach that included the behavior of groups, families, communities, organizations, cultures, and societies. This broadening in the scope of the definition has resulted in a better understanding of the contextual nature of human behavior. The contextual nature refers to both personal and social contexts or structures in which individual behavior is enacted (Robbins et al., 2005). These contextual variables constantly change to incorporate the new social, technological, economic, and cultural processes that occur in our society. As the contextual variables absorb these ever-changing processes, they inform and influence the content of human behavior theories. Accordingly, the old theoretical perspectives are re-examined, while new perspectives are proposed. This paper discusses two interrelated theories: social network theory and social capital theory and critiques their relevance in explaining human behavior for social work educators and professionals in an increasingly information-driven and electronically-interconnected global society.

This paper critically examines the influence of the structural elements of human behavior that are often neglected in social work literature (Robbins et al., 1998). It incorporates a new multi-theoretical framework that critically examines the significance of a network approach in analyzing social, ideological, and economic structures and their influence on individual actors. The author hopes that an expanded theory base will provide a holistic view of individual problems "caused by inequitable social structure" (Findley, 1978, p. 55). Accordingly, the social network and social capital theories have been applied as analytical devices, as well as descriptive tools.

\section{NETWORK PERSPECTIVES: THE MISSING DIMENSION}

Historically, social work has "borrowed human behavior theories, primarily from the disciplines of psychology and medicine" (Robbins et al., 1998, p. 14). Since well-known champion of reform in the medical profession, Abraham Flexner (1915), had questioned the lack of theoretical basis for social work to qualify as a profession, social work drew closer to clinical and psychological orientations. As a result, human behavior theories turned toward a more individualistic focus to guide social work practice (Robbins et al., 1998). This pervasive psychological orientation during the early stages of social work led to the exclusion of macro-level theories from the theoretical framework of human behavior. Macro-level theories use a broader definition of human behavior, which includes a structural analysis of large entities, such as societies, cultures, organizations, and communities.

The theoretical knowledge from sociology, anthropology, economics, political science, and social psychology has been parsimoniously used and rarely included in the core of human behavior curriculum (Coyle, 1948). Even the ecological perspective framework, which is widely used to understand human behavior, focuses primarily on the interface between people and their environment, instead of "analyzing macro-level social problems and their impact on people's lives" (Robbins et al., 1998, p. 15). However, the legacy of Jane Addams and the Hull House movement suggests that social work had had a macro-practice tradition right from its 
inception, but the profession did not follow through on a later date. This drift from its rich, macro-practice background has prompted scholars to suggest that social work had abandoned an important mission that its founder had envisaged for it (Specht \& Courntney, 1994). Though, over the last decade, some progress has been made to retrieve macro-practice from this enforced obfuscation, however, much remains to be done.

Moreover, social work scholarship, in particular, has rarely explored the possibility of social network and social capital perspectives in defining social problems. Interestingly, approaches akin to social network and social capital theory have periodically surfaced in social work literature. In the 1960s, Leichter and Mitchell (1967) studied the kinship networks of urban Jewish families and described their influence on individual decision-making processes. They called for caseworkers to take into consideration clients' social and kinship networks in their diagnosis. However, such instances of incorporating structural variables were not common in social work practice.

When a literature search was conducted for this paper, only a handful of published works could be found in social work literature that dealt with any form of social structure analysis; whereas, in other social science disciplines, empirical and conceptual works using a network perspective were found in abundance. As discussed above, some of the reasons for this slow pace in experimentation with new theoretical frameworks lie in the propensity of the social work profession to focus towards traditional clinical practice models (Kramer \& Specht, 1983). Furthermore, the methodologies to measure the benefits of social networks have developed only in the last 10 years, making it difficult for an applied profession like social work to use them.

Investment in the potential of social network and social capital theory can prove vital for social workers to understand human behavior from a network perspective. A recent study by Loeffler et al. (2004) suggested that social work needs to take into account the dynamics of clients' social networks, while designing micro, mezzo, and macro interventions. These authors further suggest that nurturing the social network and social capital of clients in their respective communities could save social policy dollars (Loeffller et al., 2004). The next section will trace the historical background of the emergence of social network and social capital theories and underline the factors that contributed to the development of their key concepts.

\section{THE EVOLUTION OF CONCEPTS}

Social network and social capital theories fall into the long and distinguished historical tradition of structural analysis. Structural analysis originated and grew across diverse interdisciplinary fields. Spencer (1982) and Durkheim (1964), in sociology, Radcliff-Brown (1959), in anthropology, de Saussure (1916), in linguistics, and, at some level, Germain and Gidderman's (1978) ecological perspective in social work have underlined the significance of understanding the structural variables in explaining the inadequacies of person-centered perspectives on human behavior. There are two distinct traditions that historically locate development of the core ideas of social networks and social capital; they are: 1) networks as structure; and 2) the inherent values and norms in network ties. 
The network as structure perspective can be traced in the work of Moreno (1934). Moreno started asking people who their friends were and what were the organizations for which they worked, he then developed a diagram of points and lines to represent relations among different social entities. Moreno termed such a diagram a sociogram and developed a distinct method to analyze the sociogram, called sociometry. Barnes (1954), however, was the first scholar to coin the term social network. According to Wasserman and Faust (1994, p. 10), the "notion of a network of relations linking social entities, or of webs or ties" evolving into a social structure "had found wide expression throughout social sciences." Recognition that social networks can be used to understand social structure came from the works of Mark Granovetter (1972) and most recently from Ronald Burt (1982).

The network-based perspective of social structure compliments the positional notions of explaining human behavior by early system theorists, including Max Weber (1947), Talcott Parsons (1951), and George Homans (1958). Moreover, the development of social network analysis as a distinct methodology has "brought the power of mathematics to the study of social systems" (Wasseman \& Faust, 1994, p. 12). A detailed outline of this historical development can be found in the work of Harary, Norman, and Cartwright (1965). The notion of network as structure, described above, is a part of social network theory; however, many scholars, including Putnam (2001) and Coleman (1998), believe that it does not take into account the active part individuals play in creating and shaping such network structure. Thus, the social capital theory intervenes to characterize certain values and norms inherent in network ties, which further explain the role of individual actors in creating advantages and disadvantages within social network structures.

The fundamental idea of social capital can be traced as far back as Alexis de Tocqueville (1966), a French diplomat who argued for the virtue of associations in American civil society in 1830. Hanifan (1920) coined the term social capital, equating it with concepts, such as family relationships, goodwill, and fellowship. In the 1960s, Schultz (1961), Becker (1964), and other economists articulated the theories of human capital. This paved the way for a broader understanding of social norms and values as capital within the social context.

It was only 19 years ago when Coleman (1988) carried out the first systemic conceptualization of social capital. He viewed social capital as a public resource that is inadvertently created by unconscious human interaction. Moreover, the value of this resource is embedded within the quality of social ties, which are determined by the existence of the degrees of trust and reciprocity within those social ties. Other theorists, such as Burt (1998), Lin (2001), Field (2003), Dasgupta (2000), Wellman and Hasse (2001), Fukuyama (1995), and Woolcock (1998) further extended the concept into different structural, social, and theoretical dimensions and thus, contributed to an interesting evolution of a complex concept.

Thus, social capital began as a comparatively simple concept and evolved into "a complex account of people's relationships and their values” (Field, 2003, p. 45). Unlike other forms of capital (physical and human), social capital is defined in multifaceted ways, broadening its dimensions and making its measurement a challenging and contentious task (Field, 2003; Wellman, 2001). Bourdieu's (1986) understanding of social capital stems from structural hierarchies of society that allow 
individuals who are better positioned in social, economic, and cultural hierarchies to use their homogenous (similar) and heterogeneous (diverse) social networks to sustain the existing power distribution that benefits them.

Finally, it was Robert Putnam, a political scientist at Harvard, who popularized the concept of social capital and articulated it as "features of social organization, such as trust, norms, and networks that can improve the efficiency of society by facilitating coordinated actions" (Putnam, 1995a, p. 169). He was the first theorist to draw a correlation between social capital and civic participation. Putnam's theory of social capital emulates the Durkheimian concept of solidarity, which is primarily based on trust and norms across social networks (Baron et al., 2000; Field, 2003; Fukuyama, 1995).

\section{SOCIAL CAPITAL AND SOCIAL NETWORK}

Social network and social capital theory in their present form were identified by Grannovatter (1973) and Bourdieu (1990) but have since been developed most extensively by Burt (1995), Portes (1998), Coleman (1988), and Putnam (1993, 1995, 2000). Social network and social capital theories are interconnected and provide a multi-theoretical framework for understanding the structural components of human behavior. Social capital theory proposes that there are some qualities and values embedded in social networks and relationships that render certain types of benefits, both instrumental and emotional, which people can use. These potential benefits depend on whom one knows and how well one knows his or her social connections. This social connectedness creates a relationship that generates a potential flow of benefits for the individuals who are connected. These benefits could appear in forms of valuable information, job creation, education dissemination, monetary or other instrumental support, and emotional support. As these qualities are embedded in our social networks or connections, they are capable of generating future benefits for some individuals. Thus, they are called social capital. Social capital refers to network ties of goodwill, mutual support, shared language, shared norms, social trust, and a sense of mutual obligation (Huysman \& Wulf, 2004).

Thus, the core idea of social capital theory develops around this value embedded in social networks (Putnam, 1993a). Moreover, the value acquired through investment in social relationships is translated into social and economic gain for individuals, but it is unlike other forms of capital —no single individual can claim ownership of this value, as it only generates through useful interactions across social networks (Coleman, 1988). This particular network characteristic of social capital generates collective behavior among social units. Coleman (1988) equated this characteristic of social capital with "public good," which forms itself inadvertently through human exchanges within their respective social networks.

Networks are constituted by a set of relational ties across a set of actors that form social structure (Scott, 2001). Network theorists argue that an understanding of social capital requires a finer-grained analysis of the specific quality and configuration of network ties (Wasserman \& Faust, 1998). Putnam (2001) distinguishes two types of networks that characteristically determine different social capital through bridging and bonding (exclusive and inclusive). Bridging refers to diverse 
networks that encompass more distant ties outside of close networks, such as acquaintances and workmates, whereas bonding refers to homogenous (similar) networks that denote ties between like-people in similar situations, such as immediate family, close friends, and neighbors (Putnam, 2000). Coleman (1988) named these bonding ties as dense and closed networks.

Before going further in this analysis, we should note that structure and networks are not to be identified as the same. Structure is a much broader concept, with many interconnected networks existing as structural components at different levels of hierarchy (Burt, 1992); whereas, "a network is a set of interconnected nodes" of single individual units (Castells, 1996, p. 470). The architecture of modern day social structures is complex and hierarchical. According to Lin (2001), it still represents the shape of a Maslow's pyramid. If the matrix of social structure is hierarchical, then the location of the positions of individual units in that matrix attain significance in accessing the embedded resources of the network structure. This positional advantage can render characteristics, such as status, prestige, class, and authority to individual position holders who could further translate these characteristics into reputation, wealth, and power, which would increase their access to embedded resources by improving the quality of their network ties (Lin, 2001). The quality of network ties depends on the degree of social capital that they could generate (Fukuyama, 1995; Scott, 2001). Thus, the location of individual units in a structure is an important determinant of the influence that a particular unit can exercise through actions.

Thus, social capital is embedded in social structure (Ostrom, 1994). The bonding ties are stronger than bridging ties, and they tend to produce more emotional, but less instrumental, support (Burt, 1992; Coleman, 1988; Lin, 2001). Strong relationships and mutual acquaintances tend to develop between people with similar social attributes, such as education, income, occupation, and age (Burt, 1998; Field, 2003). Vertical bridging ties provide opportunities for individual units to move up to networks located higher in social structure and thus improve their structural positions and gain social capital.

Burt $(1992,1998)$ further argues that social capital is equivalent to social resources that people accumulate through their positions and ties in social networks or structure. Eventually, people invest their earned social capital in various social opportunities. If people or units remain unconnected in a network, it is called network holes, which provide further investment opportunities by reaching out to unconnected entities within or across networks. According to Monge and Contractor (2003), these investments are largely motivated by self-interest. Thus, contrastingly, the benefits accumulated through participation in social networks, which are more collective in nature, could generate capital benefits that are private in nature.

Coleman (1988, p. 598) defines social capital as "a variety of different entities, with two elements in common: they all consist of some aspect of social structure, and they facilitate certain actions of actors-whether personal or corporate actors-within the structure." This definition highlights the existence of two functional concepts: 1) the presence of a social network structure and 2) an element of action/interaction. Lin (2001, p. 29) further refined this definition by calling social 
capital the "resources embedded in a social structure that are accessed and/or mobilized in purposive actions," therefore referring to the existence of resources embedded within the structure.

Hence, theoretically, the network perspective should be able to explain the following three factors: the quality and distribution of resources ingrained in a structure, how individual actors access these resources, and what kind of outcome the aforementioned resources bring about in their lives, as well as to the structure as a whole (Bourdieu, 1990; Burt, 1992; Coleman, 1988; Lin, 2001). The value of these resources can be either instrumental or relational, depending on the context of the action. As Bourdieu (1990, p. 119) rightly explained, "Social capital is the sum of the resources, actual or virtual, that accrue to an individual or group by virtue of possessing a durable network of more or less institutionalized relationships of mutual acquaintance and recognition."

\section{EMPIRICAL SUPPORT AND METHODOLOGICAL CONCERNS}

Social network and social capital theories, though they conceptually compliment each other, grew out of distinct traditions and thus follow two separate empirical lineages that often cross paths. These theories reflect both positivistic and phenomenological orientations. Social network theory uses social network analysis (SNA), a distinct methodology, for empirical research. Though SNA has existed as a mathematical concept since 1930, it was only during the 1990s that interest in SNA peaked (Carrington et al., 2005). SNA has been used mostly in sociology, economics, political, and health sciences to analyze and measure community support networks, social capital (Wellman, 2001), kinship networks, information dissemination, organizational partnerships, international trade, terrorist networks, and the spread of epidemics.

According to Carrington et al. (2005), the behavioral sciences have been showing greater interest in SNA as they explore the social context of human behavior. Baerveldt et al. (2004) applied SNA to examine whether peer relations play a role in the precipitation of delinquent behavior. SNA has been widely used in psychology to study the influence of a patient's network on schizophrenia (Baars et al., 1990). With the media attention given to terrorist activities in recent times, social scientists have used SNA to predict the logistics of terrorist operations by investigating the workings of terrorist networks (Carrington et al., 2005). Within economic sociology, social networks have been utilized widely by studies "in eliciting the role of social capital and trust for economic purposes” (Koniordos, 2005, p. 5).

The measurement of social capital has been a debatable issue in empirical research, with various researchers contributing in their own ad-hoc ways. Social capital is a multidimensional concept and thus is difficult to measure. A theoretically informed measurement approach suggests that measures of social capital vary in different network types. As a result, it would require a wide range of measures to locate the concept. Neuman (1991, p. 575) suggests that our inability to recognize social capital as a multi-dimensional concept might "muddle our empirical question;" still, many studies follow a one-dimensional approach by identifying one item that is a deductive measure of social capital. 
Both social network and social capital theories have been widely criticized for relying heavily on the quantification of empirical data and overlooking subjective phenomenon (Bollig, 2000). Social ethnographers believe that the network perspective follows a typical reasoning, such as "I know that Bob hates Mary, so, if I want to know about Mary's new boyfriend without Mary finding out, I can safely ask Bob, but I can't take what Bob says as gospel;" however, it is difficult to elicit a subjective network qualitatively (Bollig, 2000). Some scholars further believe that, by emphasizing the structural variables, social network and social capital theories have replaced qualitative approaches, like the "network therapy" that extended the boundaries of family therapy to work with personal networks (Wolfe, 1982a).

Within the methodological concerns described above, there is no denying that the social network and social capital theories posit an exciting opportunity to explain human behavior at a global level. With the growth of information communication technologies, communities across continents are quickly becoming interconnected and are contributing to the rise of a network society (Castrells, 1996). Nothing can be more appropriate for human behavior perspectives than to reposition the existing theoretical frameworks towards this emerging macro-level phenomenon.

\section{NEW CHALLENGES: THE RISE OF NETWORK SOCIETY}

During the last 15 years, we have witnessed an unprecedented spurt in technological development associated with growth of the Internet and electronic infrastructure, which have literally wired the whole world. Monge and Contractor (2003, p. 4) describe this phenomenon as "spectacular advances and convergences in computer and communication technology," which is changing the social and organizational landscapes and is resulting in the "emergence of network forms of organization as an integral part of the co-evolution of the new 'network society" (Castells, 1996, p. 10). A network is defined as a "personalized exchange among many agents" that elicits a social structure that has properties that influence human behavior and actions (Rauch \& Hamilton, 2001). The key concept of a network society is not new; however, the unprecedented rise in electronic communication due to proliferation of the Internet and the gradual trickle-down effect that it has had across different social segments, have qualified it as an emerging social context in understanding human behavior.

According to Castells (1996, p. 394), the development of electronic communication and information systems allows for an "increasing disassociation between spatial proximity and the performance of everyday life's functions: work, shopping, entertainment, healthcare, education, public services, governance, and the like." As the structural barriers become fluid and multiple bridging ties, facilitated by technological means, individuals transcend their immediate community and function virtually anywhere in the world. Thus, the architecture of social structure opens up its barriers and undergoes a "spatial transformation" (Castells, 1996, p. 10). As a result, communities become disembodied from their geographic meaning and get integrated into functional networks (Castells, 1996; Coleman, 1988). According to Castells (1996, p. 375), "today the space we live in has elements of reality and virtuality and is no longer transfixed into territories." This "space of 
flow" is characterized by the material foundation of a new culture, the "culture of real virtuality."

Social science theorists have long been interested in how changes in communication technology impact human behavior. The new millennium was characterized by the rapidly expanding Internet communication technologies, with $75 \%$ of Americans having access to the Internet by the end of 2006 (Pew Internet Report, 2006). This astronomical growth in computer-mediated communication throws new challenges to the existing theoretical frameworks for analyzing human behavior and raises pertinent macro-level questions that postulate theoretical restructuring. Do networks formed through the Internet influence human behavior? Does it accentuate structural disadvantages? Does it call for a redefinition of "social environment" as we know it? Wellman (2001, p. 2031) claims that, "when computer systems connect people and organizations, they are inherently social, because computer networks principally support social networks."

This infusion of a technology-driven lifestyle, notably in the last two decades, has necessitated fundamental changes in the way individuals, communities, and societies interact and behave across their social and political networks. However, these changes have not been accounted for within the human behavior theoretical matrix that informs social work practice. According to Vugt and Snyder (2002), rapid globalization of the local economy and the escalating spread of information networks lead to the transformation of traditional states and communities. For social workers, these trends would inspire exciting, new areas of intervention and research in which every discipline would have the opportunity to understand different perspectives on human behavior in emerging social environments. The social network and social capital theories herald such a possibility for the future of the social work profession.

\section{References}

Baars, H., Uffing, J., \& Dekkers, G. (1990). Sociale netwerk-stratagieen in de sociale psychiatrie. Antwerp: Bohn Stafleu Van Loghum.

Baerveldt, C., Van Rossem, R., \&Vermande. M. (2003). Pupils' delinquency and their social networks. A test of some network assumptions of the ability and inability models of delinquency. The Netherlands Journal of Social Sciences, 39, 107-125.

Barnas, J.A. (1954). Class and committees in a Norwegian island parish. Human Relations, 7, 39-58.

Baron, S., Field, J., \& Schuller, T. (Eds.). (2000). Social capital: Critical perspectives. Oxford: Oxford University Press.

Becker, G.S. (1964). Human capital. New York: Columbia University Press.

Bollig, M. (2000) "Staging social structures: Ritual and social organisation in an egalitarian society: The Pastoral Pokot of Northern Kenya," Ethnos, 65(3), pp. 341-365.

Bourdieu, P. (1986). The forms of capital. Handbook of theory and research for the sociology of education. New York: Greenwood Press.

Bourdieu, P. (1990). The logic of practice. Stanford: Stanford University Press.

Burt, R.S. (1992). Structural holes: The social structure of competition. Cambridge, MA: Harvard University Press. 
Burt, R.S. (1998). The gender of social capital. Rationality and Society, 10(1), 5-46.

Castells, M. (1996). The rise of the network society. Cambridge, MA: Blackwell Publishers.

Coleman, J.S. (1988). Social capital in the creation of human capital. American Journal of Sociology, 94, S95-S120.

Coyle, G. (1948). Groupwork with American youth. New York: Harper.

de Saussure, F. (1916). Course in general linguistics. New York: McGraw-Hill.

Durkheim, E. (1964). The rules of sociological method. London: Free Press.

Field, J. (2003). Social capital: Key ideas. New York: Routledge.

Findlay, P.C. (1978). Critical theory and social work practice. Catalyst, 3, 55-67.

Flexner, A. (1915). Is social work a profession? Proceedings of the National Conference of Charities and Correction (pp. 576-590). Chicago: Hildmann.

Fukuyama, F. (1995). Trust: The social virtues and the creation of prosperity. London: Hamish Hamilton.

Germain C.B., \& Gidderman, A. (1980). The life model of social work practice. New York: Columbia University Press.

Granovetter, M.S. (1973). The strength of weak ties. American Journal of Sociology, 78, 1360-1380.

Hanifan, L.J. (1920). Social capital: Its development and use. Chicago: Burdett Company.

Harary, F., Norman, R.Z., \& Cartwright, D. (1965). Structural models: An introduction to the theory of directed graphs. New York: John Wiley and Sons.

Homans, G.C. (1958). Social behavior as exchange. American Journal of Sociology, 19, 22-24.

Huysman, M., \& Wulf, V. (Eds.). (2004). Social capital and information technology. Cambridge, MA: MIT Press.

Konordos, M.S. (Eds.). (2005). Networks, trust and social capital: Theoretical and empirical investigations from Europe. Burlington, VT: Ashgate

Kramer, R.M., \& Specht, H. (1983). Reading in community organization practice. NJ: Prentice-Hall.

Leichter, H., \& Mitchell, W. (1967). Kinship and casework. New York: Russell Sage Foundation.

Lin, N. (2001). Social capital: A theory of social structure and action. Cambridge, UK: Cambridge University Press.

Loeffler, D.N., Christiansen, D.C., Tracy, M.B., Secret, M.C., Ersing, R.L., Fairchild, S.R., \& Sutphen, R. (2004). Social capital for social work: Towards a definition and conceptual framework. Social Development Issues, 26(2/3), 22-38.

Monge, P., \& Contractor, N. (2003). Theories of communication networks. New York: Oxford University Press.

Moreno, J.L. (1934). Who shall survive? Foundations of sociometry, group psychotherapy, and sociodrama. Washington, D.C.: Nervous and Mental Health Publishing Co.

Neuman, R. (1991). The future of mass audience. New York: Cambridge University Press.

Ostrom, E. (1994). Constituting social capital and collective action. Journal of Theoretical Politics, 6(4), 81-

Parsons, T. (1951). The social system. New York: Free Press.

Pew Internet and American life project reports on demographics. (2006, April 4). Retrieved February 1 , 2007, from http://www.pewinternet.org/PPF/r/171/report display.asp.

Portes, A. (1998). Social capital: Its origins and applications in modern sociology. Annual Review of Sociology, 24, 1-24.

Putnam, R. (1995a). Bowling alone: America's declining social capital. Journal of Democracy, 6, 67-78.

Putnam, R. (2000). Bowling alone: The collapse and revival of American community. New York: Simon \& Schuster.

Putnam, R. (2001). Civic disengagement in contemporary America. Government and Opposition, 36(2), 135-156. 
Radcliff-Brown, A.R. (1959). Structure and function in primitive society. New York: Free Press.

Robbins, S.P., Chatterjee, P., \& Edwards, C. (1998). Contemporary human behavior theory. Boston: Allyn \& Bacon.

Schultz, T.W. (1961). Investment in human capital. American Economic Review, 51(2), 1-17.

Scott, J. (2001). Social network analysis: A handbook ( $2^{\text {nd }}$ ed.). London: Sage.

Specht, H., \& Courtney, M.E. (1994). Unfaithful angels: How social work abandoned its mission. NY: Free Press.

Tocqueville, A. (1966). Democracy in America. New York: Harper and Row.

Vugt, M.V., \& Snyder, M. (2002). Cooperation in society: Fostering community action and civic participation. American Behavioral Scientist, 45(5), 765-768.

Wasserman, S., \& Faust, K. (1994). Social network analysis: Methods and applications. Cambridge: Cambridge University Press.

Weber, M. (1947). The theory of social and economic organization (A.H. Henderson \& T. Parsons, Eds. \& Trans.). Glencoe, IL: Free Press.

Wellman, B. (2001). Computer networks as social networks. Science, 293, 2031-2034.

Wolfe, A.W. (1982a). Improving communication between network theorists and practitioners. Paper presented at the $2^{\text {nd }}$ Annual Sun Belt Conference. Tampa, February 1982.

Woolcock, M. (1998). Social capital and economic development: Toward a theoretical synthesis and polity framework. Theory and Society, 27(2), 151-208.

\section{Author's Note:}

Address correspondence to: Dhrubodhi Mukherjee, School of Social Work, Quigley Hall 6-Mail Code 4329, Southern Illinois University Carbondale, 875 S. Normal Avenue, Carbondale, IL 62901, USA. e-mail: dhrubodh@siu.edu. 